\title{
Cerebral lymphomas: review of 70 cases
}

\author{
J Hume Adams, A G Howatson
}

\begin{abstract}
Seventy cerebral lymphomas from 37 men and 33 women were reviewed and reclassified using the modified Kiel classification. Fifty two of the patients were over the age of 50 years (age range 23-85 years). Only two patients were known to be immune deficient-one case of AIDS and one renal transplant recipient. Necropsies only were performed on 31 cases, biopsies only in 23 cases, and both biopsies and necropsies in 16 cases. Systemic tumour was found in 16 of 47 necropsy cases. All the tumours available for review were classic diffuse nonHodgkin's lymphomas. Where immunocytological studies were positive, the tumour cells were of $B$ cell origin. None was of $T$ cell origin, although reactive $T$ cells in the tumours were frequently identified. It is concluded from this and other studies that the incidence of intrinsic cerebral lymphomas is increasing.
\end{abstract}

Lymphomas may affect the central nervous system in one of four ways: (i) as a compressive lesion (usually secondary to an extradural spinal mass); (ii) as an intrinsic tumour and; (iii) less commonly, as a cause of diffuse meningeal tumour; or (iv) a non-metastatic complication of malignant disease.

There has been considerable controversy as to the nature of these tumours and the nature of the tumour cells. The history of the argument as to whether these tumours should be referred to as microgliomatosis or reticulum cell sarcoma has been reviewed in several papers..$^{1-3}$ It is now clear, however, that the controversy was related to the remarkable response of the monocyte-phagocyte system in these tumours, ${ }^{3}$ a response that remains unexplained, rather than to the tumour cells themselves.

There has been mounting interest in intrin-

Table 1 Antibody panel used in this analysis of intrinsic cerebral lymphomas

\begin{tabular}{lllll}
\hline Antibody & $\begin{array}{l}\text { Monoclonal }(\boldsymbol{m}) / \\
\text { polyclonal }(\boldsymbol{p})\end{array}$ & $\begin{array}{l}\text { Concentration } \\
\text { of primary } \\
\text { antibody }\end{array}$ & Source & Specificity \\
\hline L26 & $\mathrm{m}$ & $1 / 100$ & Dako & B cells \\
MB1 & $\mathrm{m}$ & $1 / 20$ & Clonab & B cells, some T cells \\
MB2 & $\mathrm{m}$ & $1 / 40$ & Clonab & B cells, macrophages \\
UCHL1 & $\mathrm{m}$ & $1 / 100$ & Dako & T cells, myeloid cells \\
MT1 & $\mathrm{m}$ & $1 / 20$ & Clonab & T cells, some B cells \\
MT2 & $\mathrm{m}$ & $1 / 20$ & Clonab & T cells, some B cells \\
K & $\mathrm{p}$ & $1 / 1000$ & Dako & Kappa light chain \\
$\lambda$ & $\mathrm{p}$ & $1 / 1000$ & Dako & Lambda light chain \\
\hline
\end{tabular}

sic cerebral lymphomas in recent years, particularly because of their increasing incidence, which is only partly related to immune deficiency. Indeed, it is stated in a recent review from North America, ${ }^{4}$ in which the world literature is analysed in detail, that by 1991 intrinsic cerebral lymphoma will be the most common neurological neoplasm by virtue of the increase in sporadic occurrence and in cases of AIDS.

Another reason for the renewed interest in these tumours is the increased use of immunocytochemistry, and it is now apparent that most intrinsic lymphomas in the central nervous system are diffuse non-Hodgkin's lymphomas of $B$ cell origin..$^{3-6}$

\section{Methods}

Seventy cases of intrinsic cerebral lymphomas occurring between 1961 and 1989 were reviewed. Thirty seven were male (aged 35-76 years) and 33 were female (aged 23-85 years). Two of the patients were known to be immune deficient-one was a renal transplant recipient and the other had AIDS. Necropsies only were undertaken in 31 cases and biopsies only in 23 cases, and biopsy and necropsy in 16 cases. In the 47 patients in whom necropsies were carried out, there was evidence of systemic tumour in 16 . The incidence of systemic tumour in the 23 cases for which only biopsy information was available is not known.

Material was available for comprehensive histological reassessment in 67 cases-there was no remaining tissue from the three earliest biopsy specimens-so that the tumours could be reclassified using the modified Kiel classification. ${ }^{7}$ The standard stains used were haemalum and eosin, haemalum and van Gieson, and reticulin.

Material was available for immunocytochemistry in 57 cases and a panel of monoclonal and polyclonal antibodies, reactive in formalin fixed, paraffin wax embedded sections, was used to determine the tumour cell lineage and clonality of immunoglobulin production. Sections were cut at $4 \mu \mathrm{m}$ and stained using the standard indirect immunoperoxidase method and the primary antibodies shown in table 1. Sections of normal tonsil were used as positive controls for all antibodies and in negative controls the primary antibodies were replaced with normal serum from appropriate species for each antibody. 


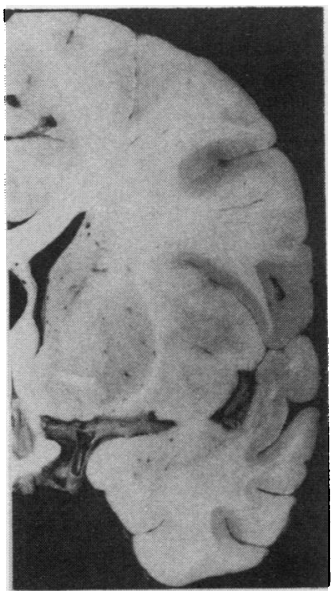

Figure 1 The insula is pale and poorly demarcated from the adjacent white matter because of infiltration by lymphoma.

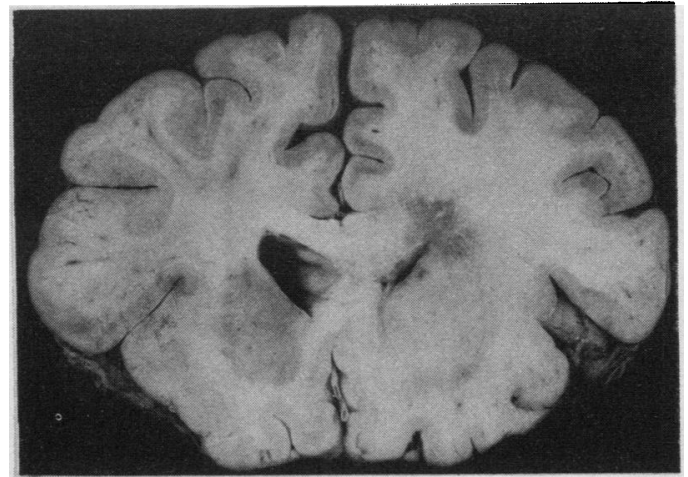

Figure 2 There is a poorly defined, rather granular tumour in the right cerebral hemisphere. The region affected is slightly expanded.

\section{Results}

INCIDENCE

This is clearly a tumour of older age groupsat least in those who are not immune deficient $-52(74 \%)$ of the cases being aged 50 years or over. There seems to be an increasing incidence in the West of Scotland, which is unlikely to be the result of better recognition and diagnosis because the Institute is a regional centre. Neurosurgery is not done in any other hospital in the West of Scotland and virtually all brains of patients dying as a result of a neurological illness are referred to the Department of Neuropathology. Furthermore, one of us (JHA) has had a particular interest in these tumours for the past 30 years.

\section{MACROSCOPIC APPEARANCES}

These vary enormously. Sometimes there was only poorly defined slight expansion of tissue with loss of intrinsic architectural markings (fig 1). Others, although poorly defined, were distinctly granular (fig 2 ). On other occasions there was a fairly well defined, firm mass (fig 3). Rarely were they cystic and indistinguishable from a cystic astrocytoma (fig 4 ). The cerebral hemispheres were the principal region affected in 37 of the 47 necropsy cases, the cerebellum in five, and the brain stem in five. In 24 cases there were multicentric lesions in the central nervous system. Inevitably, lymphomas often cause distortion and displacement of the brain, but evidence indicative of the intracranial pressure having been high during life ${ }^{8}$ was apparent in only three cases, and two of these were tumours of the cerebellum. These tumours

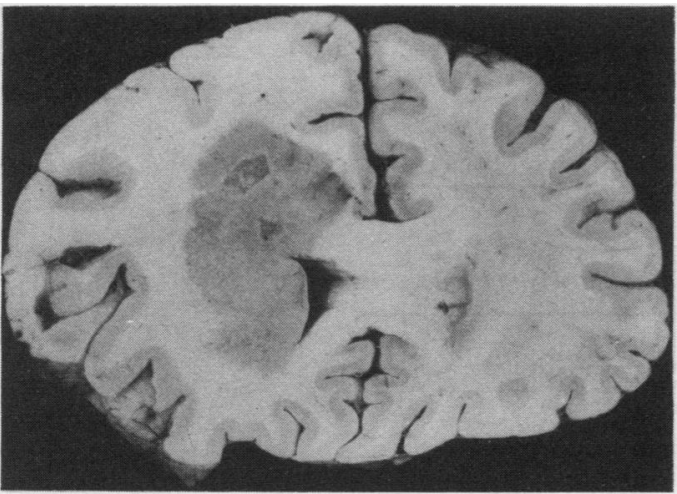

Figure 3 There is a sharply defined tumour in the left cerebral hemisphere.

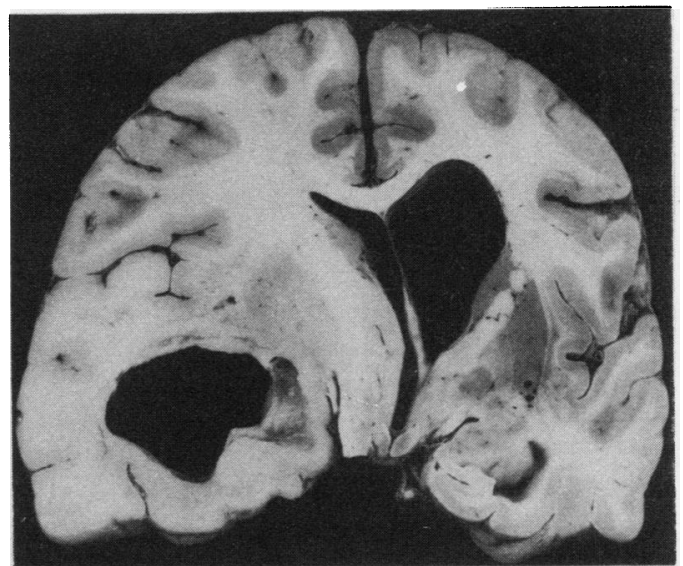

Figure 4 There is a cystic tumour in the left temporal lobe. In this instance there is considerable distortion of the brain.

therefore seem to replace brain tissue rather than act as conventional intracranial expanding lesions.

\section{MICROSCOPIC APPEARANCES}

The tumours appeared as sheets of cells that were clearly lymphoid in type. In some tumours the lymphoid cells were closely packed, while in others they were quite loosely distributed. Certain features were common to all-in particular, perivascular accentuation of tumour cells and concentric reduplication of reticulin in intrinsic blood vessels (fig 5). There were also many cells of the monocyte-phagocyte system, sometimes in the form of lipid phagocytes. Large reactive astrocytes and small lymphocytes around blood vessels were common. Very often there were small foci of tumour in macroscopically normal brain in the form of tumour cells around blood vessels and infiltrating into the adjacent neural tissue (fig 6): this was found in 23 of the 47 necropsy cases. Lymphomas extended into the subarachnoid space in 33 cases (fig 7).

As a result of this retrospective analysis, it was established that all of the tumours had the appearances of diffuse non-Hodgkin's lymphomas, and that most could be allocated to the Kiel classification (table 2).

Many tumours were high grade/large cell types, and in 12 cases the tumour cells were very pleomorphic with irregular or convoluted nuclei that did not fit any of the specific morphological subtypes of the Kiel classification.

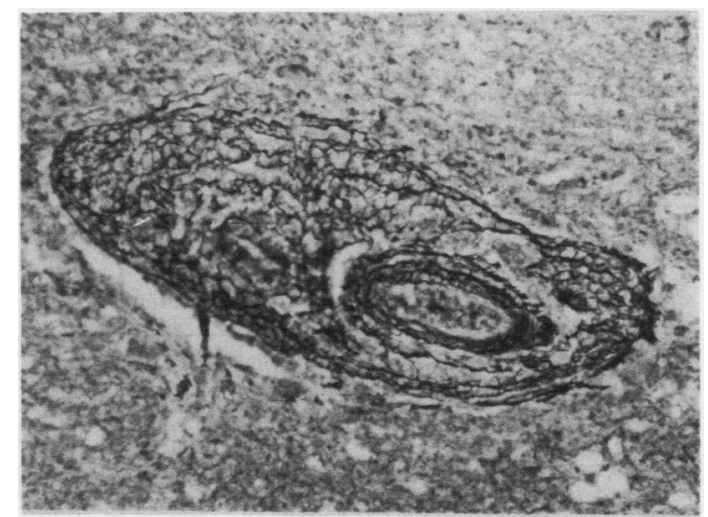

Figure 5 There is concentric reduplication of reticulin in the wall of this small blood vessel. 


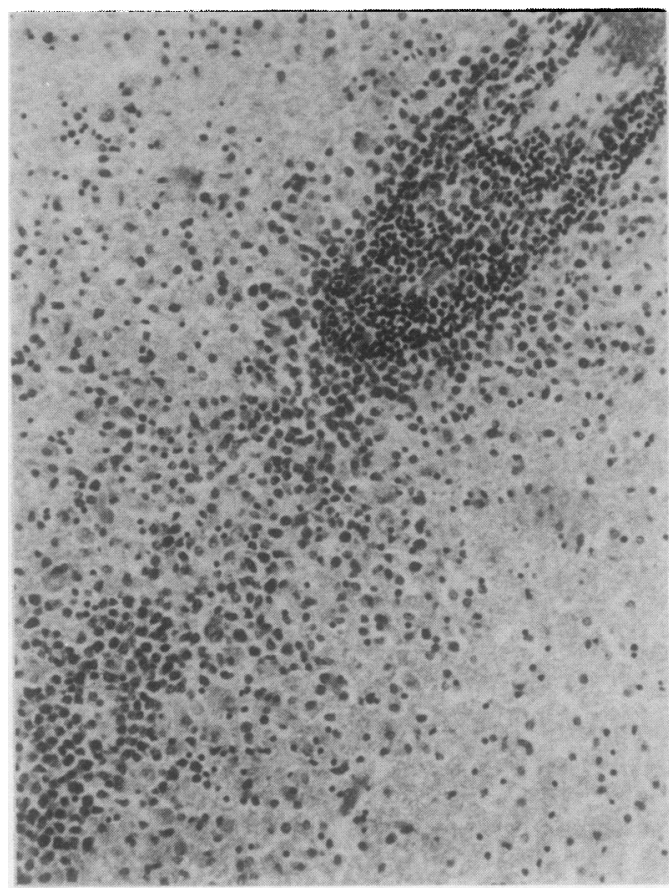

Figure 6 In addition to lymphocytes and tumour cells around a blood vessel, tumour cells are infiltrating into the adjacent tissue. This illustration is of macroscopically normal brain.

During the course of this reclassification it became apparent that there were three distinctive growth patterns which related to the degree of malignancy of the tumour. The first was characteristic of the pleomorphic and high grade lymphomas with highly cellular lesions that show very destructive growth, causing extensive replacement of grey and white matter. In these tumours there was often perivascular spread of tumour as well as some perivascular cuffing by small lymphocytes. The second pattern was noted in the diffuse centroblastic/centrocytic tumours with less destructive effects on brain parenchyma but very prominent perivascular cuffing with lymphocytes. The third pattern was more typical of the lymphoplasmacytic/oid lymphomas which seem to have a more indolent diffuse growth with or without perivascular lymphocyte cuff-

Table 2 Retrospective analysis and reclassification of 67 intrinsic cerebral lymphomas

\begin{tabular}{llllc}
\hline & CNS only & CNS + systemic & Biopsy only & Total \\
\hline Lymphocytic & & & & 0 \\
Lymphoplasmacytic/oid & 4 & 2 & 2 & 15 \\
Centroblastic/centrocytic & 8 & 7 & 8 & 17 \\
Centrocytic & 1 & 2 & & 17 \\
Centroblastic & 6 & 3 & 1 & 0 \\
Lymphoblastic & 3 & 2 & 20 & 12 \\
Immunoblastic & 9 & 16 & & 67 \\
Large cell (unclassified) & 31 & & & \\
Total & & & & \\
\hline
\end{tabular}

CNS $=$ central nervous system

Table 3 Results of immunocytochemical studies in 57 intrinsic cerebral lymphomas

\begin{tabular}{|c|c|c|c|c|c|}
\hline & \multirow{2}{*}{\multicolumn{2}{|c|}{ 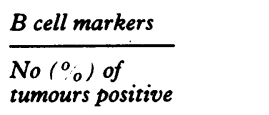 }} & \multicolumn{2}{|l|}{$T$ cell markers } & \multirow{2}{*}{$\frac{\text { Ig light chain }}{\text { No }(\%) \text { positive }}$} \\
\hline & & & $\begin{array}{l}\text { No of tumours } \\
\text { positive }\end{array}$ & $\begin{array}{l}\text { No (\%) with positive } \\
\text { reactive lymphocytes }\end{array}$ & \\
\hline $\begin{array}{l}\text { L26 } \\
\text { MB1 } \\
\text { MB2 }\end{array}$ & $\begin{array}{l}48(84) \\
39(68) \\
28(49)\end{array}$ & $\begin{array}{l}\text { UCHL1 } \\
\text { MT1 } \\
\text { MT2 }\end{array}$ & $\begin{array}{l}\text { Nil } \\
\text { Nil } \\
\text { Nil }\end{array}$ & $\begin{array}{l}47(82) \\
38(67) \\
15(26)\end{array}$ & 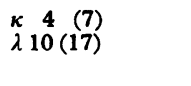 \\
\hline
\end{tabular}

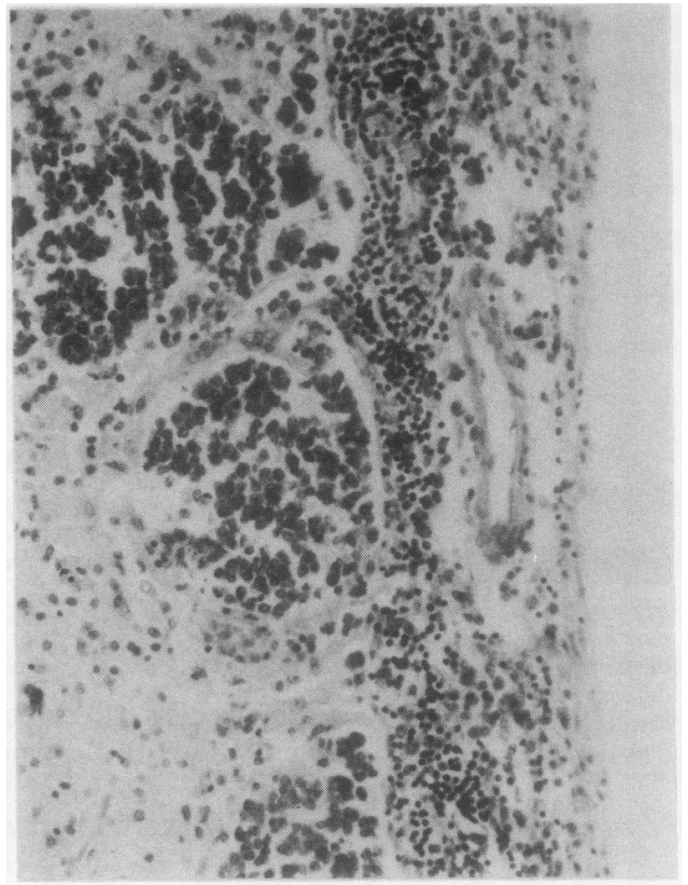

Figure 7 In addition to aggregates of subpial tumour, there are lymphocytes and tumour cells in the subarachnoid space on the right.

ing. Typically, these lymphomas grow around neurons without apparent destructive effects.

\section{IMMUNOCYTOCHEMISTRY}

Satisfactory positive staining was shown with all antibodies in the control sections. No staining was seen in the negative controls.

The results of the immunocytochemical studies are given in table 3 . There was no difference in the success rate of staining between biopsy material (short formalin fixation time) and necropsy material (long formalin fixation time). In 48 of the 57 cases examined there was positive staining of tumour cells with antibody L26, consistent with B cell origin (fig

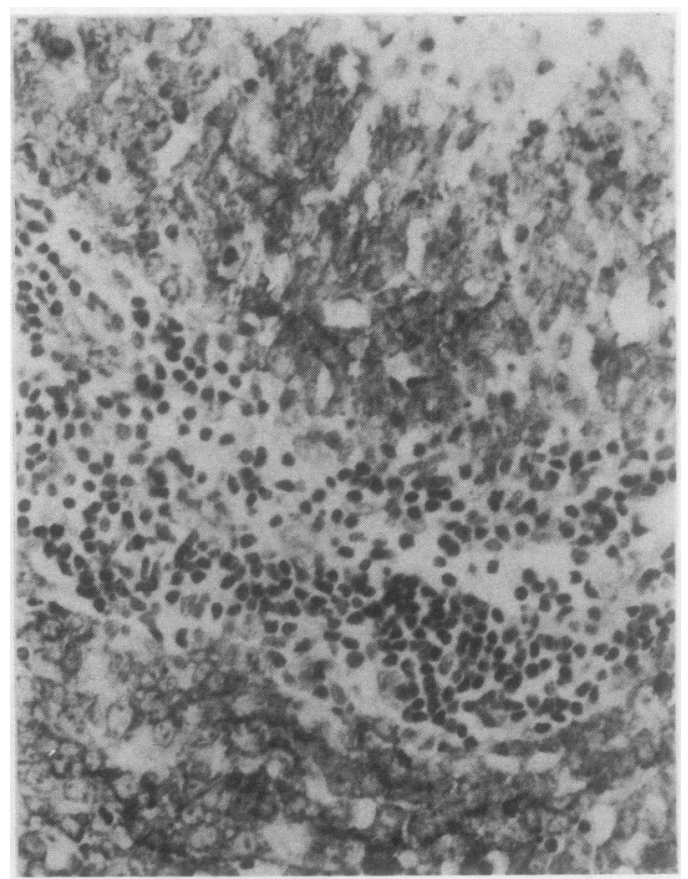

Figure 8 The cytoplasm of the tumour cells adjacent to a small blood vessel that is partly obscured by lymphocytes is positive with antibody L26. 


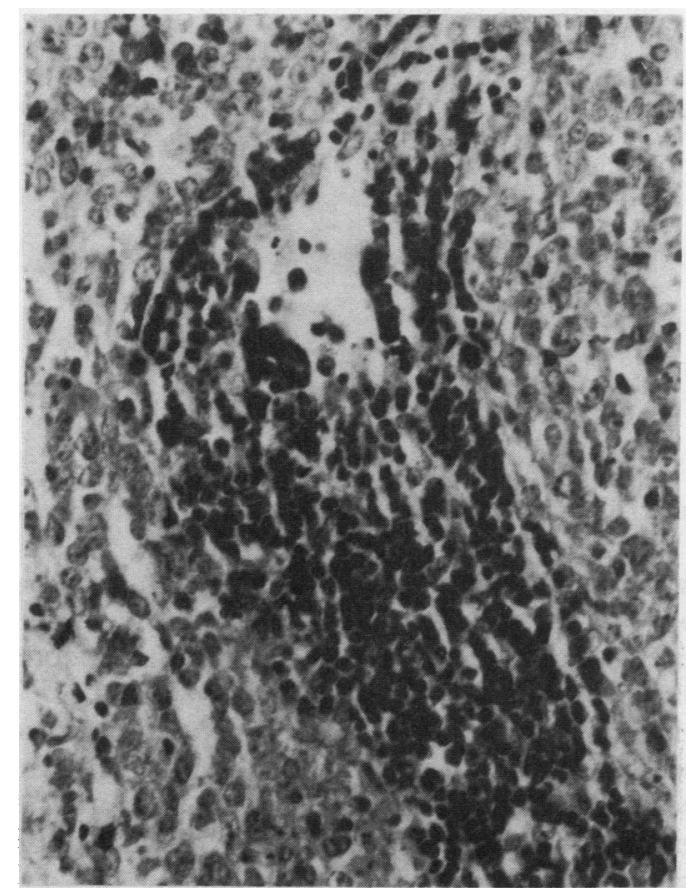

Figure 9 The lymphocytes around this small blood vessel are positive with antibody UCHL1-section immediately adjacent to that of figure 8 .

8). Confirmatory staining of B cell origin was provided in a proportion of these 48 cases by $\mathrm{MB1}$ and MB2. All of the tumours positive for MB1/MB2 were also positive for L26. The perivascular small lymphocyte cuffing was shown to be due to a reactive $T$ cell population by UCHL1 (fig 9) and other T cell antibodies. Tumour cells did not show positive staining with the $T$ cell antibodies. Light chain restriction was shown in only $14(24 \%)$ of cases.

\section{Discussion}

The recent morphological and immunocytochemical studies on lymphomas of the central nervous system referred to above were essentially based on biopsy specimens. In this series of 70 cases necropsies had been undertaken in 47 cases, from which it became apparent that regrading and immunocytochemistry were equally applicable to necropsy tissue. This study has emphasised that these tumours mainly affect the older age groups and that their incidence is increasing. Despite the great variation in macroscopic appearances, on histological examination all fall into the category of diffuse non-Hodgkin's lymphomas which could be classified in the same way as extracerebral lymphomas. There were often multiple deposits of tumour, and in half the cases small foci of lymphoma were identified microscopically in macroscopically normal brain. This is clearly of relevance to treatment. As in other recent studies, immunocytochemistry has indicated that most, if not all, intrinsic cerebral lymphomas are of B cell origin, although the occurrence of reactive $T$ cells is common.

It has long been recognised that intrinsic cerebral lymphomas can occur in the absence of tumour elsewhere in the body. This was the case in 31 of the 47 necropsy cases in our series: not only was there no macroscopic systemic tumour, but none was present in a standard histological study of representative body organs. The question that has to be addressed, therefore, is the origin of the cells in intrinsic cerebral lymphomas because there is no endogenous lymphoid tissue in the central nervous system. Two hypotheses have been proposed by Hochberg and Miller ${ }^{4}$ in their recent extensive review of this subject. One is that reactive lymphocytes are attracted to the central nervous system by latent Epstein-Barr virus or other herpes viruses, resulting in a clone being transformed into a neoplastic cell. The other hypothesis is that B lymphocytes might be transformed at some other site in the body and for some reason develop specific binding markers for the central nervous system. We have nothing to add to these hypotheses at this stage.

We are grateful to the clinicians and pathologists of the West of Scotland for the referral of the material that comprises the study We thank Dr F D Lee for advice on the morphological classification of the tumours, Mr D Murray for technical assistance, and the Department of Medical Illustration, Southern General Hospital, Glasgow.

1 Burnstein SD, Kernohan JW, Uihlein A. Neoplasms of the reticuloendothelial system of the brain. Cancer 1963; reticuloendoth

2 Adams JH, Jackson JM. Intracerebral tumours of reticular tissue: the problem of microgliomatosis and reticuloendothelial sarcomas of the brain. J Pathol Bacterio 1966;91:369-81.

3 Russell DS, Rubinstein LJ. Nervous system involvement by ymphomas. In: Pathology of tumours of the nervous system. 5th ed. London: Edward Arnold, 1989:590-607.

4 Hochberg FH, Miller DC. Primary central nervous system lymphoma. $J$ Neurosurg 1988;68:835-53.

5 Simon J, Jones EL, Trumper MM, Salmon MV. Malignant lymphomas involving the central nervous system-a morphological and immunohistochemical study of 32 cases. Histopathol 1987;11:335-49.

6 Murphy JK, O'Brien CJ, Ironside JW. Morphologic and immunophenotypic characterisation of primary brain lymphomas using paraffin-embedded tissue. Histopathol 1989;15:449-60.

7 Lennert K in collaboration with Mohri N, Stein H, Kaiserling E, Muller-Hermelink. Malignant lymphomas other than Hodgkin's disease. Berlin: Springer Verlag, 1978: 83-100.

8 Adams JH, Graham DI. The relationship between ventricular fluid pressure and the neuropathology of raised intracranial pressure. Neuropathol Appl Neurobiol $1976 ; 2: 323-32$. 